\title{
Religião e artes divinatórias na Etrúria antiga
}

\author{
NORBERTO LUIZ GUARINELLO \\ Departamento de História \\ Faculdade de Filosofia, Letras e Ciências Humanas \\ Universidade de São Paulo
}

\begin{abstract}
RESUMO: Na bibliografia contemporânea, o pensamento "racional e cientifico" greco-romano é freqüentemente contraposto à religiosidade e à superstição dos etruscos. O mundo destes seria governado por divindades terríveis e incontroláveis e a possibilidade de ação humana se restringiria à adivinhação de seus desejos, através dos sinais enviados pelos deuses, como o raio. Esta contraposição se baseia, em grande medida, em uma passagem célebre das Questões Naturais de Sêneca. Mas a interpretação desta passagem foi apressada e sua releitura nos permite repensar os dois termos dessa oposição e os próprios limites da "racionalidade" greco-romana.
\end{abstract}

PALAVRAS-CHAVE: Adivinhação, Etrúria, Sêneca, racionalidade, religião antiga.

\section{As práticas divinatórias e a cidade-estado antiga}

Prever o futuro, interpretar e decifrar o curso causal dos eventos, o desígnio dos fados... em quase todas as sociedades humanas encontramos esse desejo de adivinhar o porvir, de extrair das coisas presentes certas premonições, certos indícios. Búzios, cartas, horóscopos, artes divinatórias de diferentes tradições são, mesmo na sociedade industrial e racionalista de nossos dias, parte do cotidiano e das preocupações de amplas camadas populacionais, constituindo práticas sociais aceitas, embora não oficiais. Contudo, por seu caráter popular e, de certo modo, ilegitimo ${ }^{1}$ as práticas divinatórias encontram-se relegadas ao estatuto de mera superstição, recusadas e banidas pela grande maioria das religiões oficiais ${ }^{2}$ das grandes teologias que renunciam, assim, a uma influência e a uma forma de ação sobre o mundo que foi um dos elementos essenciais das religiões do Mediterrâneo antigo.

No mundo greco-romano, por exemplo, a adivinhação, plenamente integrada na religião do estado, era um canal privilegiado para se medir e equilibrar as relações entre sagrado e profano, para se conhecer o destino ou a vontade dos deuses, ora transformando elementos da natureza em sinais, ora em contato com a divindade (como no êxtase profético da pitonisa de Delfos). Mais que mera expressão de uma curiosidade 
individual, a adivinhação era uma prática de Estado, um instrumento de ação e de resolução de conflitos entre cidades ou entre diferentes estratégias na condição política de seus assuntos internos. As práticas divinatórias, diversamente do que ocorre no mundo moderno, tinham uma função cívica ${ }^{3}$, integrando o sagrado na vida das cidades e influindo na determinação dos atos políticos que regiam as relações entre os cidadãos e que possibilitavam sua ação comum. $\mathrm{O}$ uso que Temístocles fez do oráculo de Delfos para conduzir a guerra contra Xerxes - (Heródoto, 7, 140-5) e que possibilitou a vitória ateniense em Salamina - ou, com resultado oposto, a paralisia do exército de Nícias frente a Siracusa, após um eclipse (Tucídides, 23,50$)^{4}$, mostram com clareza a importância que tais práticas podiam assumir em momentos cruciais da vida das cidades.

Seu significado, contudo, não se restringia aos instantes de crise aguda. Para aos romanos, em particular, as artes premonitórias eram um dos eixos de sua vida politica ${ }^{5}$ modulando e cadenciando as atividades cívicas da $V r b s$. O conhecimento da predisposição divina, através da leitura dos auspícios (interpretação do vôo dos pássaros), era uma das bases do calendário político romano, antecedendo a todos os momentos importantes da vida do Estado, ut nihil belli domique [...] nisi auspicato gereretur, concilia populi, exercitus uocati, summa rerum, ubi aues non admisissent, dirimerentur (Tito Lívio, I, 36). Prodígios, eventos ocorridos contra naturam, podiam mesmo interromper a vida pública por longos períodos, prenunciando graves desastres e exigindo o cumprimento de determinados rituais de expiação ${ }^{6}$.

Desta forma, o recurso público e sistemático às práticas divinatórias foi um traço comum a muitas das culturas urbanas do Mediterrâneo antigo e seu estudo exige, do historiador contemporâneo, um distanciamento crítico com relação às nossas próprias concepções sobre o papel da advinhação no pensamento religioso e na vida social. A consciência da importância, amplidão e especificidade das práticas premonitórias na antiguidade será, como veremos, fundamental para o estudo da adivinhação entre os etruscos, dada a posição central que esta assumia em sua religião.

\section{Religião etrusca e adivinhação}

Dentre as culturas que floresceram no Mediterrâneo na segunda Idade do Ferro, a etrusca é uma das mais instigantes e menos conhecidas. Povo de origem incerta (autóctone, asiática ou ambas?), falando e escrevendo uma língua singular, os etruscos desenvolveram, a partir do século VIII a.C., um modo de vida que, a despeito das influências acolhidas da Grécia e do Oriente, manteve um caráter marcadamente original ${ }^{7}$. Como nos relatam diversos autores gregos e romanos, parte integrante desse "caráter" era uma preocupação constante com o sagrado e com o ritual, uma intensa religiosidade que gerou estranheza e admiração entre os povos vizinhos ${ }^{8}$. A despeito das dificuldades em se conhecer seu pensamento religioso, devido ao caráter escasso e tardio das fontes disponíveis ${ }^{9}$, algumas de suas características fundamentais são reiteradamente descritas 
pela tradição textual greco-romana. A religião etrusca, ao contrário da helênica ou romana, derivava seus princípios de uma revelação original: um dia, conta uma lenda repetida por várias fontes, um anão chamado Tages surgira do sulco feito por um arado e ensinara aos etruscos as artes da civilização, a organização espacial dos deuses e do universo, o modo de se conhecer a vontade divina e de se obter seu favor com ritos apropriados ${ }^{10}$. Algumas fontes atribuem parte de tais ensinamentos a uma ninfa, divindade das águas doces, chamada Vegóia (Sérvio, Ad Aen., 6, 72). Da revelação de Tages ou de Vegóia, os etruscos teriam extraido os rituais necessários à fundação de cidades e à delimitação dos campos, a arte de interpretar os raios e de ler os desígnios do sagrado no figado de animais sacrificados, a forma dos infernos e o modo de se obter a vida após a morte. Esse conhecimento do sagrado e das regras rituais de sua relação com o profano compunham o que os autores latinos denominavam a "disciplina etrusca", recolhida, ao menos tardiamente, em uma série de libri: fatales (Tito Livio, 5, 14), fulgurales, haruspicini, rituales (Cícero, De diu., 1, 72), acheruntici (Sérvio, Ad Aen., 3, 398). Preocupação central de tais libri era a interpretação dos desígnios divinos, por meio de profecias ${ }^{11}$, do exame dos raios, hierarquizados segundo a região do céu e da terra que uniam ou da hepatoscopia - a leitura dos lóbulos do figado.

A guarda dos livros, bem como o reconhecimento dos sinais divinos e sua interpretação estavam a cargo de sacerdotes específicos, especializados, donos de um saber do qual estava excluida a massa da população. Netsvis em etrusco, haruspices em latim, esses conhecedores do sagrado formavam, provavelmente, uma ordem à parte, como fazem supor a existência, em época romana, de uma ordo $L X$ haruspicum (C.I.L., XI, 3382) e alguns termos etruscos como zilkh cekhaneri (prov. equivalente a curator sacris faciundis) (Pallottino, 1965, p. 230). Sua atuação nos é conhecida, sobretudo, pelas freqüentes menções, em fontes latinas, ao seu auxílio na interpretação de portenta que afetavam o Estado romano. Conhecemos em detalhe uma dessas ocasiões, que nos é descrita por Cícero (no De haruspicum responso) e que, praticamente, resume o que sabemos sobre seu modo de agir: em 56 a.C., relata Cícero, ouviu-se um estranho rumor subterrâneo no ager latiniensis, acompanhado de um tremor de terra. Arúspices convocados da Etrúria relataram ao Senado que se tratava de ameças provenientes de Júpiter, Saturno, da deusa Tellus e de todos os deuses celestes. A causa, segundo eles, era a negligência na execução dos jogos e a profanação de antigos segredos e de lugares sagrados. A interpretação do fenômeno prenunciava discórdias civis e era preciso evitar que:

[...] pela discórdia ou desentendimento entre os melhores se preparassem delitos ou perigos contra os senadores [...] Em caso contrário, todas as províncias se colocariam sob uma única autoridade, o exército seria derrotado e ocorreria a catástrofe final. É preciso evitar igualmente que a República seja vítima de maquinações clandestinas, que criminosos adquiram cargos públicos e, finalmente, que se tente alterar a forma de governo [De har. responso, 20]. 
Os procedimentos divinatórios ocupavam, portanto, uma posição crucial no pensamento religioso etrusco e seu estudo é uma das chaves fundamentais para se penetrar na sua visão de mundo, no seu modo de compreender a posição dos homens sobre a terra e sua relação com os deuses. No entanto, essa arte de adivinhar o futuro desenvolvida pelos etruscos nos é conhecida apenas através de fontes romanas $\operatorname{tardias}^{12} \mathrm{e}$ de alguns raros documentos arqueológicos ${ }^{13}$. A documentação textual, que se situa entre o final da República e o Baixo-Império, fornece-nos informações de qualidade variável sobre essas práticas, numa época em que a cultura etrusca já se "romanizara" profundamente e entrara em contato com as correntes de pensamento do mundo helenístico. Desta forma, mesmo quando dispomos de fontes que parecem basear-se em originais etruscos, os procedimentos divinatórios e as concepções sobre o universo que lhes eram subjacentes mostram profundas influências externas ${ }^{14}$, tornando dificil, e por vezes impossível, discernir um núcleo de concepções e práticas originais (Dumézil, 1974, p. 632).

Tais limitações de nossa documentação são, sem dúvida, mais evidentes nas fontes que se propõem a descrever a doutrina que fundamentava os processos de adivinhação. Tais fontes são, quase sempre, interpretações romanas de concepções etruscas malcompreendidas. Mesmo naquelas fontes, contudo, que, como vimos, descrevem a atuação de arúspices etruscos, sem se preocupar com seu fundamento religioso, o que encontramos é sua aplicação a realidades especificamente romanas, em geral no contexto das lutas sociais do final da República. A reconstituição das práticas divinatórias entre os etruscos depende, portanto, de uma utilização criteriosa e crítica de tal documentação e da plena consciência dos limites da informação disponivel.

\section{Sêneca e a adivinhação etrusca}

Um dos textos mais significativos - e, sem dúvida, o mais explorado - para o conhecimento da concepção etrusca do universo e do papel da adivinhação na relação entre homens e deuses encontra-se no livro segundo de um tratado filosófico escrito no século I de nossa era: as Questões Naturais de Sêneca, que discute longamente as causas naturais de determinados fenômenos atmosféricos e seu significado para a previsão do futuro ${ }^{15}$. Uma passagem, em particular, tem sido utilizada para caracterizar a especificidade da religião etrusca frente a gregos e romanos:

Nisto os etruscos, cuja ciência da investigação dos raios é muito desenvolvida, diferem de nós: enquanto achamos que os raios são emitidos porque nuvens se chocaram, eles julgam que as nuvens se chocam para que raios sejam emitidos. Pois, como relacionam todas as coisas à divindade, são de opinião que o significado das coisas não está em sua ocorrência, mas que ocorrem para significar. [Sêneca, Questões Naturais, II, 32] 
Baseando-se neste pequeno trecho, reforçado por várias menções à religiosidade dos etruscos entre os autores antigos ${ }^{16}$, desenvolveu-se na bibliografia uma reconstrução da relação sagrado/profano entre os etruscos que se diferencia nitidamente do que se supõe fosse tal relação para gregos e romanos. Para M. Pallottino, por exemplo, cuja visão da religião etrusca é, ainda, muito influente, o trecho mencionado revelaria

outro aspecto que pertence à mentalidade primitiva dos etruscos [...] a interpretação ilógica e mística dos fenômenos naturais que, persistindo até época muito recente, contrasta dramaticamente com a racionalidade cientifica dos gregos. [Pallottino, 1965 , p. 222]

Desta maneira, os etruscos se caracterizariam por uma concepção "primitiva" do universo ${ }^{17}$, na qual o micro-cosmos refletiria especularmente as alterações e tendências do macro-cosmos (como fundamento da adivinhação e da leitura dos figados, dos portenta e dos raios) e onde os homens se encontrariam submetidos ao arbítrio divino. Para R. Bloch, igualmente:

no mundo etrusco [...] até o fim de sua história, todas as ações dos homens estavam totalmente dependentes da vontade dos deuses. Os fenômenos mais evidentes e mais facilmente explicáveis, tanto da natureza como dos seres vivos, permaneceram para eles numa ligação indissolúvel com a presença e a ação constante das forças misteriosas do Céu e dos Infernos. [Bloch, 1966, p. 142]

Ou, ainda, Pallottino:

Em todas essas concepções e práticas [...] tem-se a impressão de um abandono, de uma abdicação da vontade humana frente à divindade, que se revela na dupla obsessão pelo conhecimento e atuação da vontade divina, ou seja, no desenvolvimento das práticas divinatórias e na rígida minuciosidade do culto. [Pallottino, 1965, p. 221]

Para entendermos em que medida a passagem de Sêneca corrobora, ou não, tais afirmações, é necessário investigá-la mais de perto. As considerações que faz sobre a interpretação etrusca dos fenômenos naturais são emitidas em termos de uma oposiçào entre um illi (eles=etruscos) e um nos (nós), que concebem o universo diferentemente. Tal contraposição fornece o quadro dentro do qual se definem ambos os termos, de modo que não podem ser compreendidos em si, mas apenas pela forma como se opõem no texto. Para se compreender as afirmações de Sêneca sobre a adivinhação etrusca, portanto, é essencial analisar, não apenas o que efetivamente diz sobre esta, mas também aquela outra concepção, que lhe serve de contraponto: trata-se de investigar o que Sêneca entende por "nós" e como esse "nós" encara os fenômenos naturais e a previsão do futuro a partir deles.

A interpretação corrente na bibliografia contemporânea, que, contudo, não dedica muita atenção a este segundo termo, tende a ver ai uma clara referência à cientificidade greco-romana, contraposta ao misticismo etrusco. "Nós", assim, remeteria ao mundo 
helenístico-romano e à sua racionalidade, como quer M. Pallottino (1965, p. 222), ou ainda, na visão universalista de Dumézil, aos cientistas e à ciência em geral: "A oposição ressaltada por Sêneca não é entre a ciência grega e a religião etrusca, mas entre toda ciência e toda religião" (Dumézil, 1974, p. 634)

Para avaliarmos em que medida tais afirmações interpretam corretamente o sentido da passagem, é necessário analisar o contexto discursivo em que se insere o trecho e como se coaduna com a própria posição do autor sobre a adivinhação. Para tanto, vale a pena citar integralmente a passagem em consideração e investigar o que, efetivamente, Sêneca entende pelo jogo de contraposições que estabelece.

O capítulo XXXII das Questões Naturais inicia-se com uma discussão genérica sobre o significado dos raios na predição do futuro:

Deve-se acrescentar ${ }^{18}$ [diz Sêneca] que os raios mostram o futuro, e não dão apenas sinais de um ou outro fato, mas freqüentemente anunciam uma seqüência completa de fatos subseqüentes, e com disposições evidentes e muito mais claras do que se fossem escritas. Nisto os etruscos [...] [segue-se a passagem citada acima]. Contudo, as coisas ocorrem do mesmo modo, seja a significação seu propósito ou sua conseqüência. Mas de que maneira significam, se não são enviadas com esse propósito? Do mesmo modo que as aves, que não se movem para vir ao nosso encontro, nos dão auspícios conforme vão para a esquerda ou direita.

Sêneca, portanto, em nenhum momento opõe a adivinhação etrusca a uma suposta "racionalidade greco-romana", rejeitando aquela como crendice e superstição. Ao contrário, afirma expressamente sua conviç̧ão na prioridade dos fenômenos de indicarem eventos futuros. O que põe em contraste, na verdade, são duas formas diversas de se conceber tal propriedade. Para Sêneca, os fenômenos e as coisas que ocorrem são capazes de nos informar sobre o que vai acontecer, mas apenas porque são parte de um mesmo todo universal, manifestação de um mesmo logos, de uma mesma causa inicial que se expressa em cada uma delas. $\mathrm{O}$ fundamento da predição é, assim, a unidade essencial entre micro e macrocosmos, sendo as práticas divinatórias atos de leitura, de decifração do todo através de suas partes:

A ordem dos eventos desenvolve-se de modo diferente [do que crêem os etruscos]: indícios do que há de vir se mostram em toda parte, alguns nos são familiares, outros desconhecidos. Tudo aquilo que ocorre é signo de algo que irá ocorrer [...] onde existe uma seqüência ordenada, é possivel a predição [...] não há animal cujo movimento e direção não predigam alguma coisa. Obviamente não notamos todos, mas apenas alguns. $\mathrm{O}$ auspício é um fato do observador, daquele que dirige sua atenção para as ocorrências, mas existem igualmente outros sinais, aos quais não se presta atenção. [Sêneca, $Q N, 2,32]$

Sêneca, portanto, não admite a existência de objetos ou eventos privilegiados para a previsão do futuro. Todas as coisas são passiveis de leitura, tudo indica o que há de 
acontecer e nosso conhecimento do futuro é limitado, tão-somente, por nossa capacidade de ler, nas coisas e eventos, as informações ali contidas. De umas conhecemos a chave de interpretação, de outras não. As coisas significam porque ocorrem (significant quia facta sunt), ou seja, porque sua ocorrência expressa sua pertinência ao todo, ao logos, à causa universal. E o todo, Deus, a natureza, manifesta-se em suátotalidade em cada uma de suas partes, porque não há graus na verdade, nem verdades parciais (fatum unum est, 2, 34; fatum fulmine mutari non potest. Quidni? Nam fulmen ipsum fati pars est, 2, 35).

Tais consideraçães nos permitem, por outro lado, identificar o "nós" de Sêneca. Não se trata, aqui, de gregos ou romanos entendidos em termos genéricos, nem tampouco de pensadores "racionais" ou "científicos", numa oposição que os autores modemos transferem anacronicamente a Sêneca, mas de um "nós" bem mais restrito. Na verdade, as Questões Naturais são articuladas como um diálogo entre o autor e Lucílio, no qual Sêneca procura explicar e justificar ao sobrinho e amigo as teorias sobre a natureza desenvolvidas pelos filósofos estóicos. $O$ segundo termo da oposição, portanto, remete à bem conhecida concepção do universo do estoicismo, à idéia da unidade fundamental de todas as coisas e da pré-determinação do curso causal dos eventos (Long, 1974, p. 163).

Podemos, agora, retomar ao texto de Sêneca inicialmente citado e nos perguntarmos sobre o significado da contraposição que estabelece. Sêneca opõe à adivinhação etrusca uma concepção estóica ${ }^{19}$ das práticas divinatórias que se caracteriza pela universalidade dos sinais premonitórios, pela pré-determinação dos eventos futuros e pela possibilidade generalizada de leitura do futuro a todos os que se disponham a compreender a natureza. A isto, contrapõe uma adivinhação (a etrusca) marcada pelo caráter finalista dos presságios e pela restrição destes a determinadas categorias de eventos. Isso implica que, para Sêneca, a especificidade (e a estranheza) da concepção etrusca reside no caráter de mensagem particular de que se revestem os presságios. Estes não são resultado da ordem natural das coisas, mas ações específicas de determinados deuses (em especial de Júpiter e dos deuses denominados superiores et inuoluti ${ }^{29}$ ), empregando meios particulares (como os raios e os portenta) e privilegiados, para aconselharem ou reclamarem dos homens. Sua leitura, portanto, depende não de uma compreensão da ordem do mundo enquanto razão, mas de um saber específico, místico, de origem divina.

A oposição entre ambas as concepções não se limita, contudo, a estes aspectos. Como a seqüência do texto de Sêneca deixa claro, os etruscos tinham uma noção peculiar da liberdade humana frente às manifestações da vontade divina. Longe de determinarem um destino pré-fixado e imutável, as mensagens dos deuses deixavam ampla margem de interpretação e reação por parte dos homens ${ }^{21}$. Os desígnios divinos podiam ser aplacados ${ }^{22}$, desviados, retardados $(2,43)$ ou mesmo revogados por outras mensagens, transmitidas por sinais hierarquicamente superiores (como os raios) ${ }^{23}$. Como atestam outras fontes, o saber acumulado nos livros permitia aos arúspices retardar os eventos anun- 
ciados pelo destino em até dez anos ${ }^{24}$ ou ainda, através de um jogo interpretativo, manipular o significado das mensagens divinas, alterando a disposição e interpretação dos significantes segundo seus interesses ${ }^{25}$.

Podemos, assim, traçar um quadro das oposições estabelecidas por Sêneca entre as duas formas de conceber os presságios. Estes são:

Para Sêneca

sem finalidade específica

universais, presentes em todos os eventos

imutáveis/pré-determinados

legíveis - pela observação e conhecimento da natureza, por qualquer ser humano
Para os etruscos

mensagens especificas

particulares, presentes em categorias determinadas e hierarquizadas de eventos

passíveis de manipulação

legíveis - pela posse de um saber

específico, religioso, restrito à

camada sacerdotal

Este quadro, que resume os resultados de nossa investigação até aqui, permite-nos fixar algumas conclusões. Em primeiro lugar, a adivinhação etrusca configura-se como um procedimento de predição do futuro, nem mais, nem menos racional do que aquele aceito por Sêneca. A oposição que este ressalta não é articulada como um confronto entre racionalidade/ciência versus irracionalidade/superstição, mas entre duas maneiras distintas de se pensar o universo e o destino. Frente ao determinismo de Sêneca, na verdade, a concepção etrusca parece mesmo conferir um maior grau de autonomia à ação humana - embora a possibilidade dessa ação se restrinja a um grupo fechado de sacerdotes. Por outro lado, se é verdade que as concepções religiosas dos etruscos e sua visão de mundo diferiam daquelas presentes no mundo greco-romano, tal diferença não residia, como vimos, no recurso sistemático à adivinhação, como se este fosse a marca de um suposto pensamento "primitivo e irracional", nem tampouco na importância e no significado cívico e social que lhe eram atribuídos.

A estranheza sentida por gregos e romanos tem, a nosso ver, outras origens, que devem ser buscadas na especificidade da organização social etrusca e no lugar aí ocupado pela religião. Ao contrário da maioria das cidades gregas e latinas, as cidades etruscas mantiveram, por longo tempo, uma estrutura fechada e extremamente aristocrática, sendo sua população, até onde alcançam nossas fontes, dividida em categorias estritamente hierarquizadas e distintas ${ }^{26}$. Dentro dessa sociedade, e novamente em oposição ao mundo greco-romano, o saber religioso permaneceu privilégio de um grupo restrito e especializado, intimamente ligado à aristocracia e ao poder, aos quais fornecia instrumentos ideológicos para a manutenção de sua posição e de sua legitimidade.

Sob este prisma, as idéias correntes sobre o pensamento etrusco - que se apóiam fortemente no trecho de Sêneca que estudamos - parecem provir de um duplo preconceito, que permeia parte dos estudos sobre o Mediterrâneo antigo. Por um lado, ainda é 
forte a tendência a se supervalorizar a cultura grega, erigindo-a num modelo ideal de pensamento racional e "científico", que nos informa mais sobre as elaborações ideológicas do século passado e deste do que sobre as realidades concretas do mundo urbano na antiguidade. A essa idealização do "helênico" (e, indiretamente, do romano, no que este tem de grego) corresponde um conceito vago de cultura periférica, "bárbara" por definição e, logo, primitiva e irracional. Falseiam-se, assim, os dois termos de comparação: nem a cultura grega era tão racional e laica, nem os etruscos tão supersticiosos como nos faz crer a moderna bibliografia. A nosso ver, apenas superando-se essa dicotomia anacrônica, e reinsertando os procedimentos divinatórios no contexto social que lhes dava sentido, será possível aprofundar as pesquisas sobre o pensamento religioso e a visão de mundo dos etruscos.

\section{Notas}

1- Empregamos este termo no sentido que the é atribuido por Pierre Bourdieu. cf. Bourdieu, in Ortiz, 1983, p. 82-92.

2- A repressão oficial às práticas divinatórias não foi mera conseqüência, no Ocidente, da ascensão do cristianismo como religião de Estado. Estudos recentes demonstram a anterioridade da perseguição e marginalização dos adivinhos, que ocorre já no século II d.C. Cf. o estudo de Denise Grodzynski, 1974, p. 267-94.

3- Cf. Vernant, 1974, p. 9-28.

4- Nícias, que segundo Tucídides dava excessivo crédito às práticas divinatórias, retardou a retirada de seu exército por 27 dias, enquanto espiava os presságios negativos de um eclipse lunar. $\mathrm{O}$ atraso foi fatal para as forças atenienses, que foram aniquiladas.

5- Veja-se, a respeito, Bloch, 1976, p. 73-9.

6- São inúmeros os casos mencionados pelas fontes. Apenas a título de exemplo veja-se Tito Lívio, 20, 2, relativo ao ano de 172 a.C. Uma lista anual dos prodígios observados em Roma durante o período republicano foi elaborada, no início do século III d.C., por Julius Obsequens: o liber prodigiorum.

7- Sobre o desenvolvimento da Etrúria e o modo de recepção das influências externas veja-se o nosso "Classe e cultura na Etrúria arcaica", 1987, p. 49-62.

8- Por exemplo, Tito Livio, 5, 1: gens ante omnes ea magis dedita religionubus, quod excelleret arte collendi eas; Amóbio, Ad. Gent., 7,26: Etruria - genetrix et mater superstitionum.

9- Vide nota 12.

10-Este mito nos é relatado, em detalhe, por Cícero, em seu De diuinatione, 2,23: Tages quidarn dicitur in agro Tarquiniensi, cum terra araretur et sulcus altius erat impressus, exstitisse repente et eum affatus esse qui arabat. Is autem Tages, ut in libris est etruscorum, puerili specie dicitur uisus sed senili fuisse prudentia [...] Tum illum plura locutum multis audientibus qui omnia eius uerba exceperint litterisque mandauerint; omnem autem orationem fuisse eam qua aruspicina continetur, eam postea creuisse rebus nouis cognoscendis et ad eadem illa principia referendis. Haec accepimus ab ipsis, haec scripta conseruant, hunc fontem habent disciplinae.

11- Possuímos uma de tais profecias, preservada no Corpus Agrimensorum Romanorum (Lachman, p. 350). Trata-se da famosa profecia de Vegóia a Arruns Velthymnus e que nos fornece 
na Etrúria antiga

um exemplo do conteúdo e forma desse gênero divinatório entre os etruscos:

Scias mare ex aethera remotum. cum autem Iuppiter terram Aetruriae sibi uindicauit, constituit iussitque metiri campos signarique agros. sciens hominum auaritiam uel terrenum cupidinem, terminis omnia scita esse uoluit. quos quandoque quis ob auaritiam prope nouissimi octaui seculi data sibi homines malo dolo uiolabunt contingent atque mouebunt, sed qui contigerit moueritque, possessionem promouendo suam, alterius minuendo, ob hoc scelus damnabitur a diis si serui faciant, dominio mutabuntur in deterius. sed si conscientia dominica fiet, caelerius domus extirpabitur, gensque eius omnis interiet. motores autem pessimis morbis et uulneribus efficientur membrisque suis debilitabuntur. tum etiam terra a tempestatibus uel turbinibus plerumque labe mouebitur. fructus saepe ledentur decutienturque imbribus atque grandine, caniculis interient, robigine occidentur. multae dissenssiones in populo. fieri haec scitote, cum talia scelera committuntur. propterea neque fallax neque bilinguis sis. disciplinam pone in corde tuo. Sobre esta profecia, que talvez remeta a realidades políticas etruscas do século II a.C., veja-se por último Turcan, 1976, p. 1009-19.

12- As principais fontes são o De haruspicum responso e o De diuinatione de Cícero; a Historia Naturalis de Plínio; as Saturnales de Macróbio e duas fontes tardias: o De ostentis de Lido e o De nuptiis Mercurii et Philologiae, de Marciano Capela, além de várias informações esparsas nas obras de antiquários, escoliastas e lexicógrafos, como Varrão, Sérvio e Festo.

13- Destes o mais significativo, sem dúvida, é o figado de bronze de Plasência (reproduzido em Pallottino, op. cit., Pl. XXVIII). Para a representação de uma cena de aruspicina num espelho estrusco veja-se Mansueli, 1968, p. 3-19.

14- Cf. Piganiol, 1953, p. 340.

15- A importância do texto advém do fato de Sêneca, ao descrever a doutrina etrusca dos raios, basear-se em uma obra escrita pelo nobre etrusco e arúspice Aulo Cecina, que fora amigo de Cícero (Cf. Ad Fam., 6, 6, datada de 46 a.C.).

16- Vide supra, nota 8.

17- Veja-se também Grenier, 1947, p. 77.

18- A oração, introduzida por um interrogativo quid?, deve ser relacionada a licet poneas, do capítulo anterior. Tratando-se de uma interrogacão retórica, optamos por traduzi-la afirmativamente. 19- É importante lembrar que a concepção de Sêneca é, na verdade, mais grega do que propriamente romana. Como nota $\mathrm{R}$. Bloch, a religião romana dava pouca importância para a adivinhação do futuro em si. Os auspícios forneciam, sobretudo, sinais favoráveis ou negativos para a execução de ações concretas. Cf. Bloch, 1976, p. 73-9.

20- Cf. Sêneca. Questoes Naturais, 2, 41.

21- Cf. Bloch, 1976, p. 54.

22- Vide Cícero, Catil., 3, 19.

23- Cf. Sêneca, Questões Naturais, 2, 34.

24- Sérvio, Ad Aen., 3, 398: sciendum secundum aruspicinae libris et sacra Acheruntia quae Tages composuisse dicitur, fata decem annis quadam ratione diferri.

25- Como atesta uma anedota, preservada por várias fontes, sobre a descoberta de uma cabeça humana, intacta, nas fundações do templo de Júpiter Capitolino (pressagiando o grande poderio de Roma) e as tentativas de um arúspice etrusco de transferir o presságio para sua cidade. Cf. Tito Lívio, 1, 55.; Dioniso de Halicarnasso, IV, 59-61; Plínio, HN, 28, 15.

26- Veja-se, por exemplo, Heurgon, 1970, p. 29-41. 


\section{Referências Bibliográficas}

BLOCH, R. Os etruscos. Lisboa: Verbo, 1966.

BLOCH, R. Prodigi e divinazione nel mondo antico. Roma: Newton Compton, 1976.

BOURDIEU, P. Gostos de classe e estilos de vida. In: ORTIZ, R. (org.). Pierre Bourdieu. São

Paulo: Ática, 1983.

DUMEZIL, G. La religion romaine archaque. Paris: Payot, 1974.

GRENIER, A. Les religions étrusque et romaine. Paris; PUF, 1947.

GRODZYNSKI, D. Par la bouche de l'empereur. In: VERNANT, J. - P. (dir.). Divination et rationali-té. Paris: Seuil, 1974.

GUARINELLO, N. L. Classe e cultura na Etrúria arcaica. Revista Brasileira de História, São Paulo, v. 7, n 13, 1987.

HEURGON, J. Classes et ordres chez les étrusques. In: Recherches sur les structures sociales dans l'antiquité classique. Paris: Éditions du CNRS, 1970.

LONG, A. A. La filosofia helenística. Madrid: Revista de Occidente, 1974.

MANSUELI, G. "Individuazione e rappresentazione storica nell'arte etrusca". Studi Etruschi, Roma, v.36, 1968.

PALLOTTINO, M. Etruscologia. Buenos Aires: Eudeba, 1965.

PIGANIOL, A. Les étrusques, peuple d'Orient. Cahiers d'Histoire Mondiale, Paris, v. 1, $\mathbf{n}^{\circ} 2$, 1953.

TURCAN, R. Encore sur la prophétie de Vegoie. In: L'Italie pré-romaine et la Rome republicaine. Roma: École Française, 1976.

VERNANT, J.-P. Paroles et signes muets. In: VERNANT, J.-P. (dir). Divination et rationalité, op. cit.

GUARINELLO, N. L. Religion et arts divinatoires en Étrurie antique. Clássica, São Paulo, 4 : 123-133, 1991.

RÉSUMÉ: Dans la bibliographie contemporaine, la pensée "rationelle et scientifique" gréco-romaine est souvent opposée à la religiosité et à la superstition des étrusques. Le monde de ceux-ci serait gouverné par des divinités terribles et incontrolables et la possibilité d'action humaine se limiterait à la divination de leurs désirs par les signes envoyés par les dieux, comme la foudre. Cette opposition entre deux visions distinctes du monde s'appuie, en grande partie, sur un passage célèbre des Questions Naturelles de Sénèque. Mais l'interprétation du passage a étè hâtive et sa relecture nous permet de répenser les deux termes de cette opposition et les limites mêmes de la "rationalité" gréco-romaine.

MOTS CLÉS: Divination, Étrurie, Séneque, rationalité, religion ancienne. 